\title{
Introducing the St. Louis Fed Price Pressure Measure
}

\author{
Laura E. Jackson, Department of Economics, Bentley University \\ Kevin L. Kliesen, Research Officer and Business Economist \\ Michael T. Owyang, Assistant Vice President and Economist
}

n January 2012, the Federal Reserve joined many other central banks in adopting a numerical inflation target: 2 percent over the medium term. Monetary policy tends to affect the economy with a lag, so prudent monetary policymaking in an inflation-targeting regime requires a forecast of future inflation over the medium term.

The Federal Reserve, like most central banks, devotes considerable resources to monitoring and analyzing large volumes of economic data and forecasting key economic series such as inflation. The problems and questions associated with forecasting future inflation have been well studied, including which measure of the price level to forecast and whether to use one particular forecasting model, average across several models, or simply use the consensus of professional forecasters. ${ }^{1}$

Policymakers usually want to know-to the extent possible-the probability that inflation over the next four or eight quarters will exceed the inflation target. Or, if inflation is very low, they may also want to know the probability that inflation will fall below zero (deflation). ${ }^{2}$ Specifically, if Fed policymakers perceive a relatively high probability that inflation will rise above the 2 percent target rate over the next year, then the probability that the FOMC will raise the federal funds target rate likely exceeds the probability that the FOMC will reduce the federal funds target rate. Thus, assessing inflation's likely path over some horizon matters to policymakers and those in financial markets.

To help policymakers, financial market participants, and others who have an interest in assessing future inflation probabilities, the Federal Reserve Bank of St. Louis has developed an index called the price pressures measure (PPM). ${ }^{3}$ The PPM measures the probability that the expected inflation rate (12-month percent changes) over the next 12 months will exceed 2.5 percent. We construct a PPM for both the consumer price index (CPI) and personal consumption expenditures price index (PCEPI). Since the FOMC's inflation target is measured in terms of the PCEPI, this essay will focus on that measure.

In technical terms, the PPM index is constructed from an ordered probit model that is augmented with nine "factors." A factor-augmented model is a common method of incorporating a large amount of data in a parsimonious fashion. The nine factors, comprising 104 separate data series, are grouped in the following categories: (1) consumer price indexes, (2) producer price indexes, (3) commodity prices, (4) housing and commercial property prices, (5) labor market indicators, (6) financial variables, (7) inflation expectations, (8) business and consumer survey data, and (9) foreign price variables.

\section{Assessing inflation's likely path matters to policymakers and those in financial markets.}

The ordered probit model provides probabilities that inflation will exceed 2.5 percent, on average, over the next 12 months. But the model also allows us to assess the probability that inflation will average something different. In our original article, ${ }^{4}$ we structured the model to assess the probability that inflation will fall within one of four bins: less than zero (deflation); 0 percent to 1.5 percent; 1.5 percent to 2.5 percent; and more than 2.5 percent. We could also assess probabilities for other outcomes. For example, we could condense the second and third bins into one, leaving three sets of probabilities: Inflation will be less than zero (deflation) over the next 12 months, inflation will average between 0 percent and 2.5 percent, and inflation will be greater than 2.5 percent.

The figure shows the PPM constructed from our preferred specification since January $1995 .{ }^{5}$ Since the mid- 


\section{St. Louis Fed Price Pressures Measure Probability that Headline PCE Inflation Exceeds 2.5 Percent Over the Next Year} (12 months ending in October 2016)

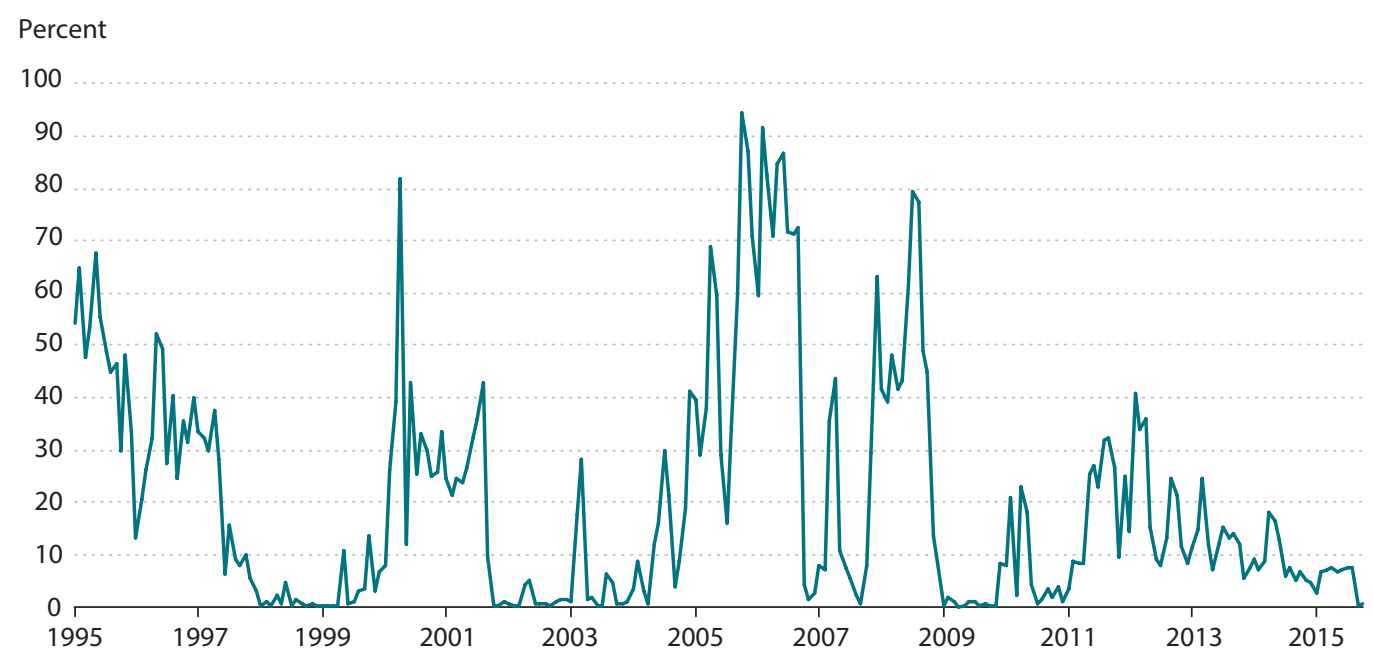

NOTE: Data through October 2015.

SOURCE: Federal Reserve Bank of St. Louis.

1990s, there have been four periods-broadly speakingwhen the PPM exceeded a probability of 0.5 (that is, 50 percent). Inflation was highest in the mid-2000s and the PPM exceeds 0.5 for several months during this period. But during this most recent business expansion, with inflation averaging less than 2 percent, the PPM averages well under 0.5. As of October 2015, the PPM predicts a zero percent probability that PCEPI inflation will average more than 2.5 percent over the next 12 months.

The PPM is another instrument that policymakers and financial market participants can add to their tool kit to monitor the near-term outlook for inflation. The Federal Reserve Bank of St. Louis will regularly update the PPM shortly after the release of the monthly PCEPI.

\author{
Notes \\ ${ }^{1}$ Faust and Wright (2013) provide an extensive survey of the inflation- \\ forecasting literature. \\ 2 See Yellen (2014). \\ 3 The authors thank Lowell R. Ricketts for initial and on-going research support \\ in the development of the PPM. \\ 4 This essay is a condensed version of Jackson, Kliesen, and Owyang (2015). \\ ${ }^{5}$ We have two separate lag-length specifications of each independent variable: \\ 1 and 6 lags. Our preferred specification is the 1-lag model.
}

\section{References}

Faust, Jon and Wright, Jonathan H. "Forecasting Inflation," in Graham Elliott and Allan Timmermann, eds., Handbook of Economic Forecasting. Volume 2A. Amsterdam: North Holland, 2013, pp. 2-56.

Jackson, Laura E.; Kliesen, Kevin L. and Owyang, Michael T. "A Measure of Price Pressures." Federal Reserve Bank of St. Louis Review, First Quarter 2015, 97(1), pp. 25-52.

Yellen, Janet L. "Monetary Policy and the Economic Recovery." Remarks at the Economic Club of New York, April 16, 2014; http://www.federalreserve.gov/newsevents/speech/yellen20140416a.htm. 